\title{
Variáveis físico-químicas da água em microbacia reflorestada com Eucalyptus no médio Vale do Paraíba
}

\author{
Maureen Voigtlaender ${ }^{1}$ \\ Marco Aurélio Freitas Lopes ${ }^{2}$ \\ Juliano Ferreira Dias ${ }^{3}$ \\ ${ }^{1}$ Universidade de São Paulo - USP/ESALQ \\ 13400-970 - Piracicaba - SP, Brasil \\ maureen@esalq.usp.br \\ ${ }^{2}$ Guapuruvu Reflorestamento \\ Avenida Marechal Castelo Branco, 354 \\ 13840-060 - Mogi Guaçú - SP, Brasil \\ maurelio.lopes@terra.com.br \\ ${ }^{3}$ Fibria \\ Rodovia General Euryales de Jesus Zerbine, Km 84 - Distrito de São Silvestre \\ 12340-010 - Jacareí - SP, Brasil \\ juliano.dias@fibria.com.br
}

\begin{abstract}
The physicochemical properties of water, sediment and nutrients mainly relate directly between forest management and water quality. We analyzed the physicochemical conditions of water in the Eucalyptus reforested area, based on 3 hydrological indicators and patterns of CONAMA Resolution. 357. Samples were collected from the catchment during the period of December 2007 to September 2008 in a catchment of 23 hectares located in the middle Paraíba Valley and the physical and chemical variables were determined using standard methods of the American Public Health Association. The results were compared to the extreme limits of stability as a means of evaluating the quality of water in the area of management and determined the average, maximum and minimum for the CONAMA. Only suspended solids higher value than both the extreme limits of stability as the standards of CONAMA. Therefore, the hypothesis stating that in areas with steep slopes to forest silvicultural practices should provide more specific, in order to allow the maintenance of hydrological processes and the production potential of the soil.
\end{abstract}

Keywords: physicochemical properties of water, Eucalyptus, forest management, Paraíba Valley.

\section{Introdução}

A bacia hidrográfica ou microbacia pode ser entendida como uma área onde a precipitação é coletada e produzida para seu sistema de drenagem natural, onde o movimento de água superficial inclui todos os usos da água existentes na localidade. A área da bacia hidrográfica tem influência sobre a qualidade da água produzida com o deflúvio e, consequentemente, os diferentes usos do solo sobre a qualidade da água (Lima, 1996).

As práticas da colheita florestal e da silvicultura interrompem o processo natural da ciclagem de nutrientes, resultando em um aumento direto da concentração dos nutrientes na água. A diminuição do potencial produtivo do solo está diretamente ligada às perdas dos macronutrientes na solução do deflúvio, e na alteração da qualidade da água.

Os sedimentos e os macronutrientes relacionam-se diretamente entre o manejo florestal e a qualidade da água. Utilizando-se a microbacia como unidade ecossistêmica de planejamento do manejo florestal existem indicadores de sustentabilidade relacionados com a manutenção dos processos hidrológicos e da qualidade do manejo florestal (balanço hídrico, picos de vazão, sedimentos em suspensão, turbidez, condutividade elétrica, fósforo, oxigênio dissolvido, potássio, temperatura da água e macroinvertebrados bentônicos), com a manutenção do potencial produtivo do solo (nitrogênio, fósforo, potássio, cálcio, magnésio e 
sedimentos em suspensão) e com a manutenção do equilíbrio do ecossistema aquático (oxigênio dissolvido, nitrogênio, fósforo, temperatura da água, sólidos em suspensão, $\mathrm{pH}$ e macroinvertebrados bentônicos) (Câmara, 2004).

O principal objetivo do trabalho foi analisar as condições físico-químicas da água em uma microbacia de 23 hectares reflorestada com Eucalyptus, baseado nos indicadores hidrológicos e nos padrões da Resolução CONAMA n ${ }^{\circ} 357$.

\section{Material e Métodos}

A área de estudo sobre a avaliação das variáveis físico-químicas da água foi realizada em uma microbacia de $1^{\text {a }}$. ordem (Strahler, 1957) de 23 hectares reflorestada com Eucalyptus no município de Monteiro Lobato. Os solos predominantes são Neossolos litólicos à Argissolos Vermelho-amarelos (EMBRAPA, 1999).

O município de Monteiro Lobato (Figura 1), a leste do Estado de São Paulo, nas coordenadas de $23^{\circ} 00^{\prime} \mathrm{S}$ de latitude e $45^{\circ} 48^{\prime}$ 'W de longitude, a $132 \mathrm{~km}$ de distância de São Paulo. Inserida no médio Vale do Paraíba (bacia do Rio Paraíba do Sul) a uma altitude média de 685 metros, o clima regional, segundo Köppen é do tipo tropical (Cfb), mesotérmico com verão ameno e sem estação seca no inverno. A precipitação medial anual é de $2200 \mathrm{~mm}$, com um excedente hídrico de $1283 \mathrm{~mm}$ e uma evapotranspiração potencial anual de $1039 \mathrm{~mm}$ (Sentelhas, 1999).

O médio Vale do Paraíba caracteriza-se por uma variedade de condições de declividade bem como de classes de relevo, em virtude de uma formação geológica antiga. A região está inserida entre as Serras do Mar e da Mantiqueira que apresentam vales profundos e escalonados, com desníveis altimétricos superiores a 2000 metros em suas escarpas (Florenzano \& Czordas, 1993).

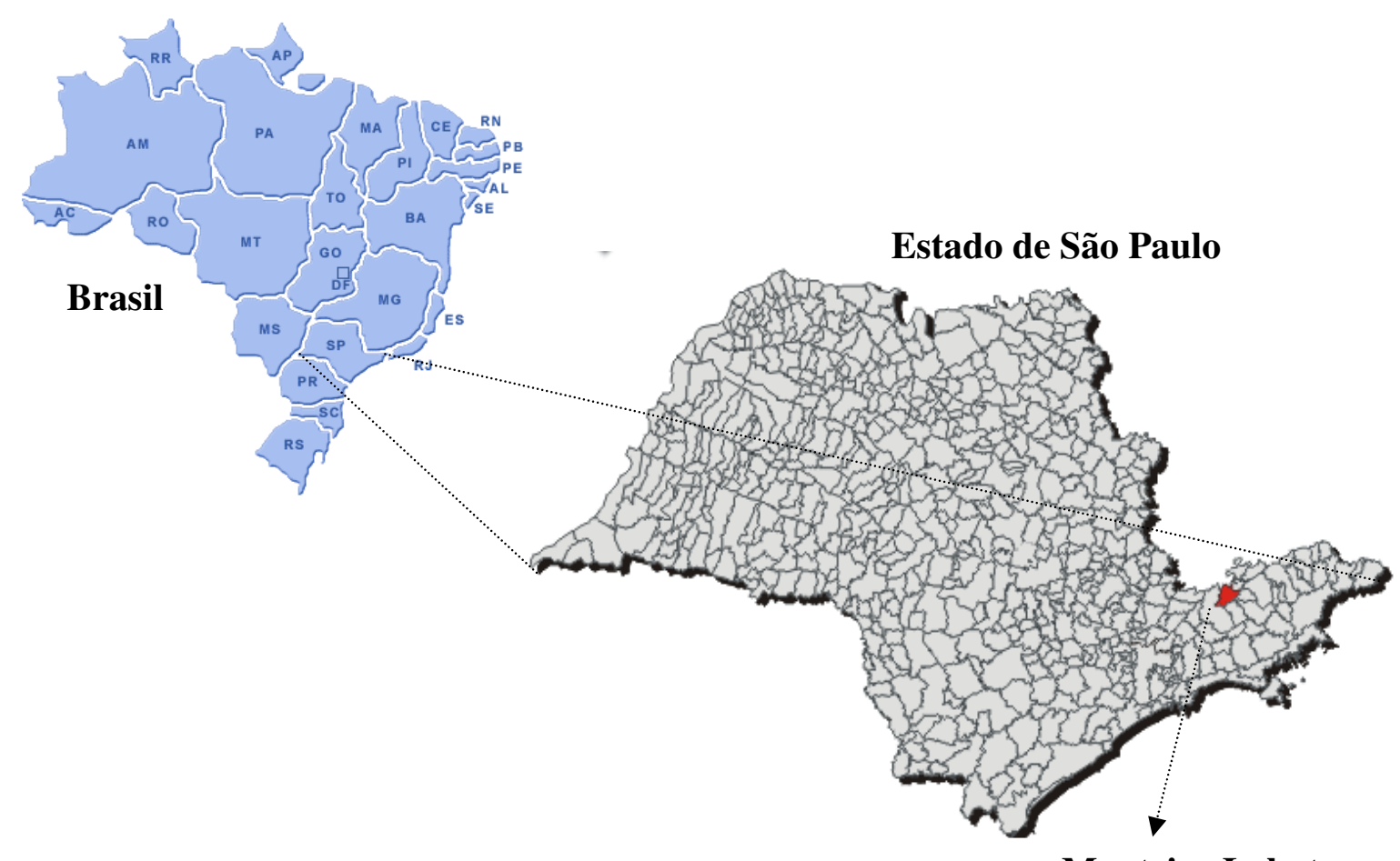

Monteiro Lobato

Figura 1. Localização do município de Monteiro Lobato, na região sudeste do Brasil, especificamente a leste do Estado de São Paulo 
Para o período de dezembro de 2007 a setembro de 2008, a precipitação foi de $1054 \mathrm{~mm}$, com uma temperatura média de $18{ }^{\circ} \mathrm{C}$ e as temperaturas mínimas registradas variaram de 2 a $20{ }^{\circ} \mathrm{C}$ e as temperaturas máximas variaram de 14 a $36^{\circ} \mathrm{C}$ e o mês mais seco foi julho (Figura 2).

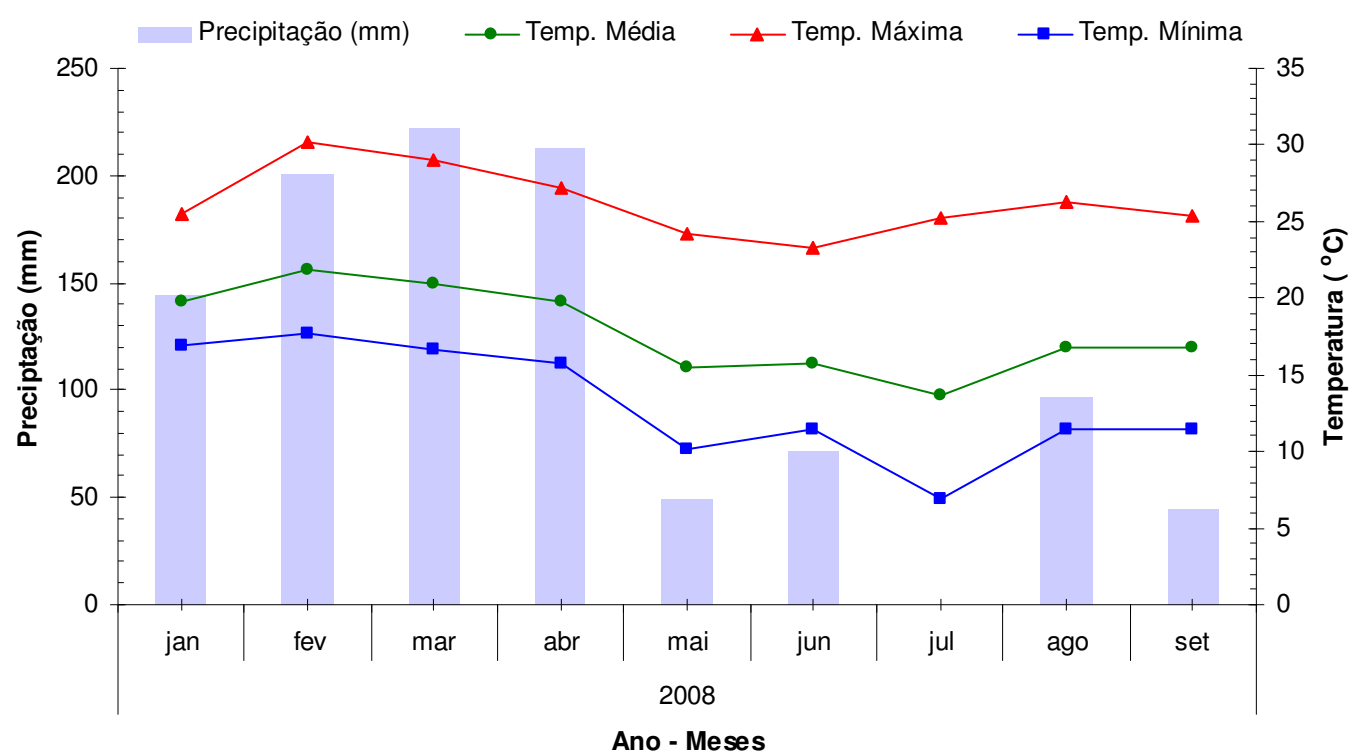

Figura 2. Precipitação pluviométrica mensal $(\mathrm{mm})$, temperatura $\left({ }^{\circ} \mathrm{C}\right)$ máxima, mínima e médias registradas próximas à microbacia para o período de janeiro a setembro de 2008

A microbacia possui uma declividade entre $20 \%$ e $40 \%$ com um relevo de forte ondulado a montanhoso. O mapa de declividade (Figura 3) permite analisar a declividade das vertentes da microbacia e mostrar a distribuição das inclinações do relevo, sendo uma característica importante avaliação para os processos erosivos e do arraste de material para o curso d'água (Mendonça, 1999).

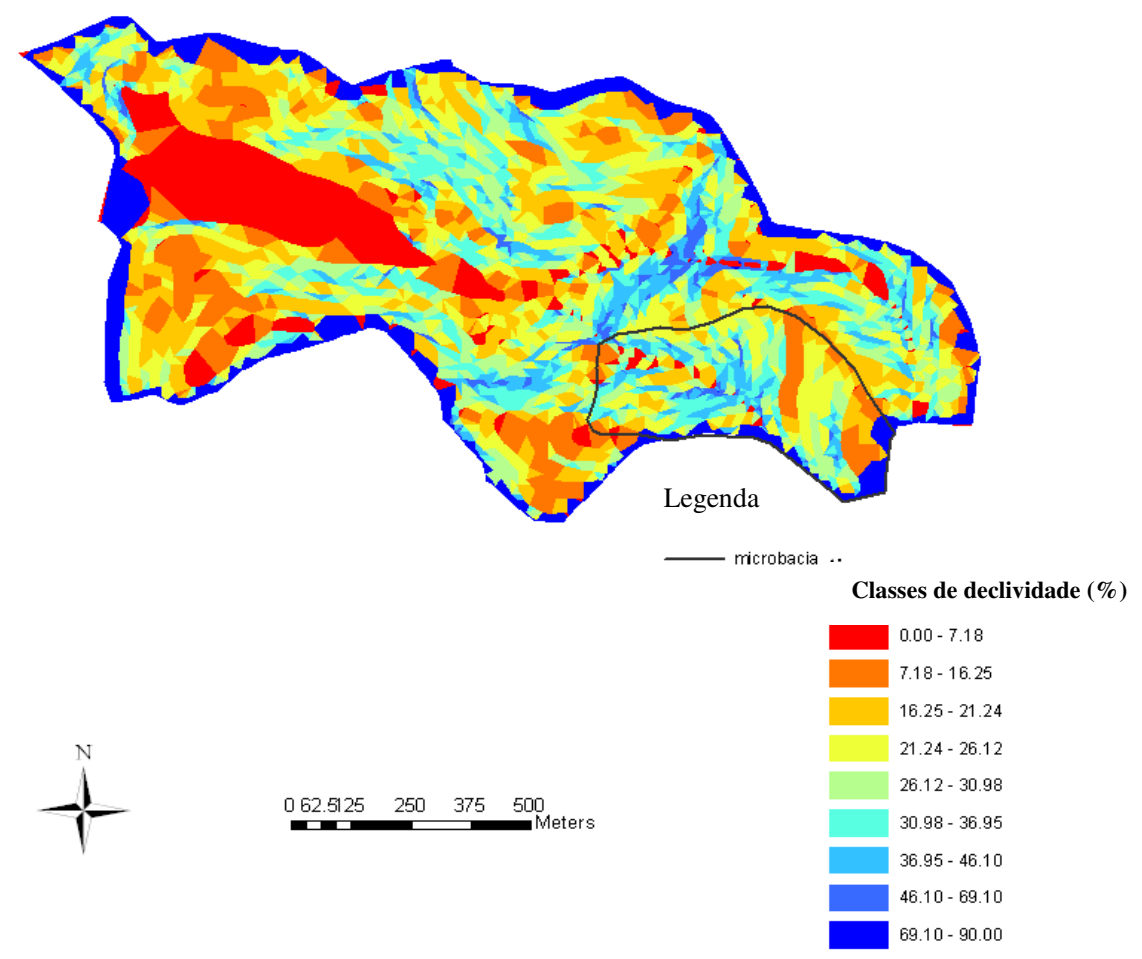

Figura 3. Mapa de declividade da microbacia reflorestada com Eucalyptus 
As coletas de água foram realizadas quinzenalmente durante o período de dezembro de 2007 a setembro de 2008 em um ponto previamente determinado e georeferenciado. As amostras de água foram coletadas e armazenadas em garrafas de polietileno de $1000 \mathrm{ml}$, previamente lavadas com solução de $\mathrm{HCl} 10 \%$ e seguidamente com água deionizada e água do riacho mantido a refrigeração de $4^{\circ} \mathrm{C}$.

As variáveis químicas determinadas para o estudo foram $\mathrm{N}_{\text {total }}, \mathrm{NO}_{3}^{-}, \mathrm{NO}_{2}^{-}, \mathrm{P}_{\text {total }}, \mathrm{Ca}^{2+}$, $\mathrm{Mg}^{2+}, \mathrm{Mn}, \mathrm{B}, \mathrm{Fe}^{2+}$ e as físicas foram turbidez, $\mathrm{CCE}, \mathrm{pH}$, sólidos suspensos, óleo/graxa e óleo mineral (Resolução CONAMA $\mathrm{n}^{\circ}$. 357). As concentrações foram determinadas de acordo com métodos padronizados pela American Public Health Association (1998).

Aos resultados das concentrações das variáveis físico-químicas foi calculado a média, desvio-padrão, máximo e mínimo e o coeficiente de variação. Somente foram apresentadas graficamente as concentrações das variáveis que apresentaram flutuações nas suas concentrações durante o período do estudo. As amostras de água de janeiro (1) e fevereiro (1) foram retiradas da análise por apresentarem concentrações fora dos padrões para as variáveis fósforo total e turbidez.

Análises paramétricas foram realizadas para as variáveis físico-químicas. Com a ausência dos requisitos básicos para a estatística paramétrica foi realizado o teste não paramétrico de Spearman para determinar as correlações com $5 \%$ de probabilidade.

Foram avaliadas também as variáveis químicas nitrato, fósforo, potássio, cálcio, magnésio e físicas $\mathrm{pH}$, condutividade, sedimentos, turbidez e cor para identificar possíveis impactos hidrológicos do reflorestamento de Eucalyptus sobre a qualidade da água.

\section{Resultados e Discussão}

O nitrato apresentou uma tendência de aumento na concentração da água ao longo do período amostrado, variando entre 0,1 a $3,5 \mathrm{mg} \mathrm{L}^{-1}$. Essa tendência poderia ser explicada pela sazonalidade entre as estações chuvosa e seca, aumentando a concentração nos meses mais secos e por uma maior deposição de material vegetal em decomposição.

O cálcio e o magnésio não apresentaram uma tendência muito clara nas concentrações, oscilando próximos aos valores médios para o período. Embora o magnésio apresentou uma concentração máxima de $1,6 \mathrm{mg} \mathrm{L}^{-1}$, o coeficiente de variação foi $40 \%$ menor que o encontrado para o cálcio.

A condutividade elétrica (CCE) e o pH mantiveram-se próximos à média. Os sólidos suspensos apresentaram uma alta variabilidade nas concentrações, que variaram de 20 a 680 $\mathrm{mg} \mathrm{L}^{-1}$. Contudo, no maior período do estudo estas concentrações estiveram abaixo da média (Figura 4).

Apenas as variáveis turbidez e condutividade elétrica apresentaram ambas correlações

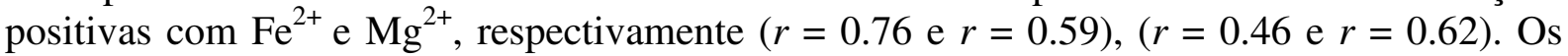
maiores valores observados foram para as correlações entre turbidez e condutividade elétrica $(r=0.76)$. Destacou-se também uma correlação positiva entre o $\mathrm{pH}$ e nitrato $(r=0.70)$ (Figura 5).

A turbidez nos corpos d'água tende a ser maior em regiões com solos erodíveis onde a precipitação pode carregar as partículas de argila, silte e fragmentos de rochas (Von Sperling, 1998). No entanto, não se observou uma tendência clara entre a turbidez e os sólidos suspensos (correlação positiva de $r=0.38$ ) que respondem principalmente aos detritos orgânicos e inorgânicos.

A condutividade elétrica da água tende a aumentar com a elevação da temperatura e com uma maior concentração de íons dissolvidos (Feitosa \& Manoel Filho, 2000). Embora não foram realizadas análises das rochas na microbacia, observou-se uma correlação significativa

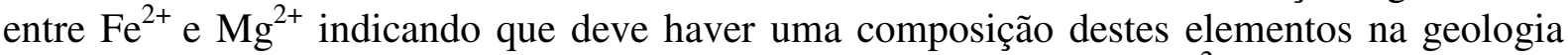
que são liberados para as águas do riacho. $\mathrm{Na}$ região as perdas de $\mathrm{Mg}^{2+}$ são maiores que as entradas pela precipitação (Ranzini \& Lima, 2002). 
(doi:10.4136/serhidro.27)

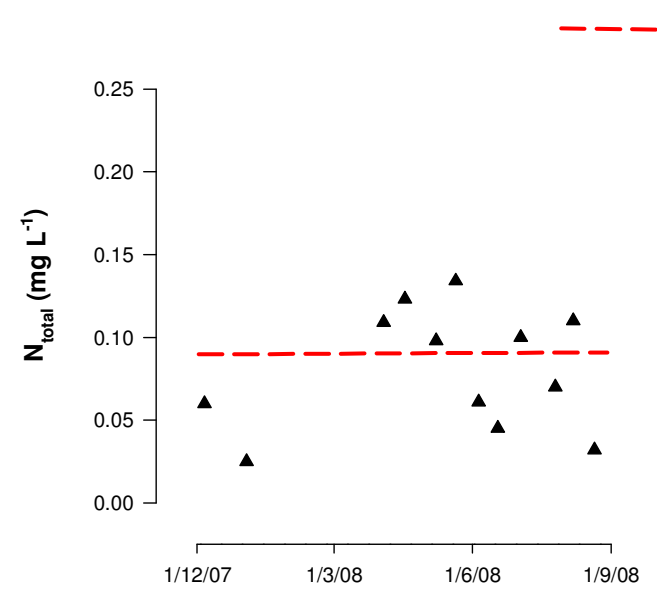

média anual
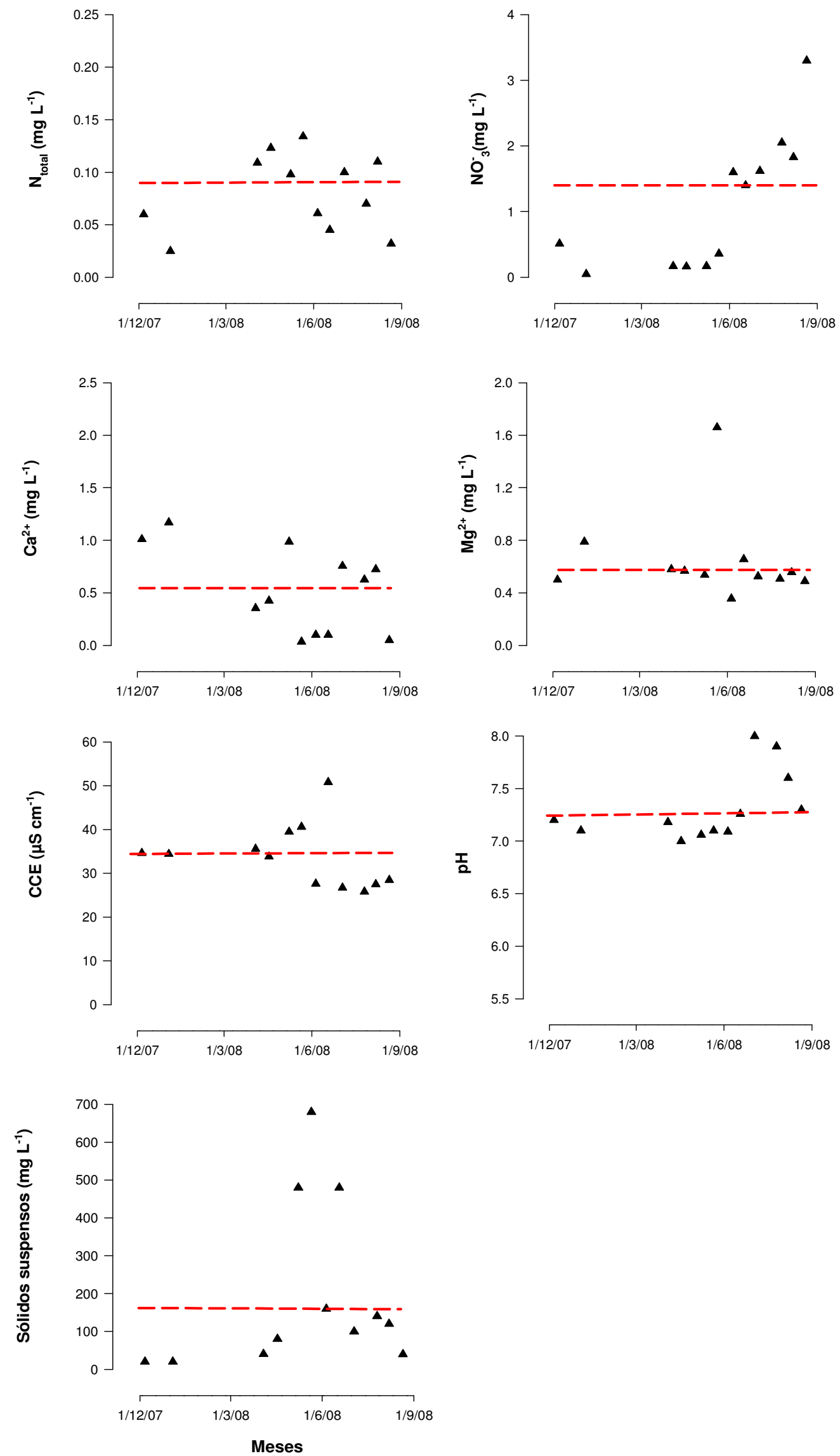

Figura 4. Análise das variáveis $\mathrm{N}_{\text {total }}, \mathrm{NO}_{3}^{-}, \mathrm{Ca}^{2+}, \mathrm{Mg}^{2+}, \mathrm{CCE}, \mathrm{pH}$ e sólidos suspensos na água da microbacia reflorestada com Eucalyptus para o período de dezembro de 2007 a setembro de 2008 

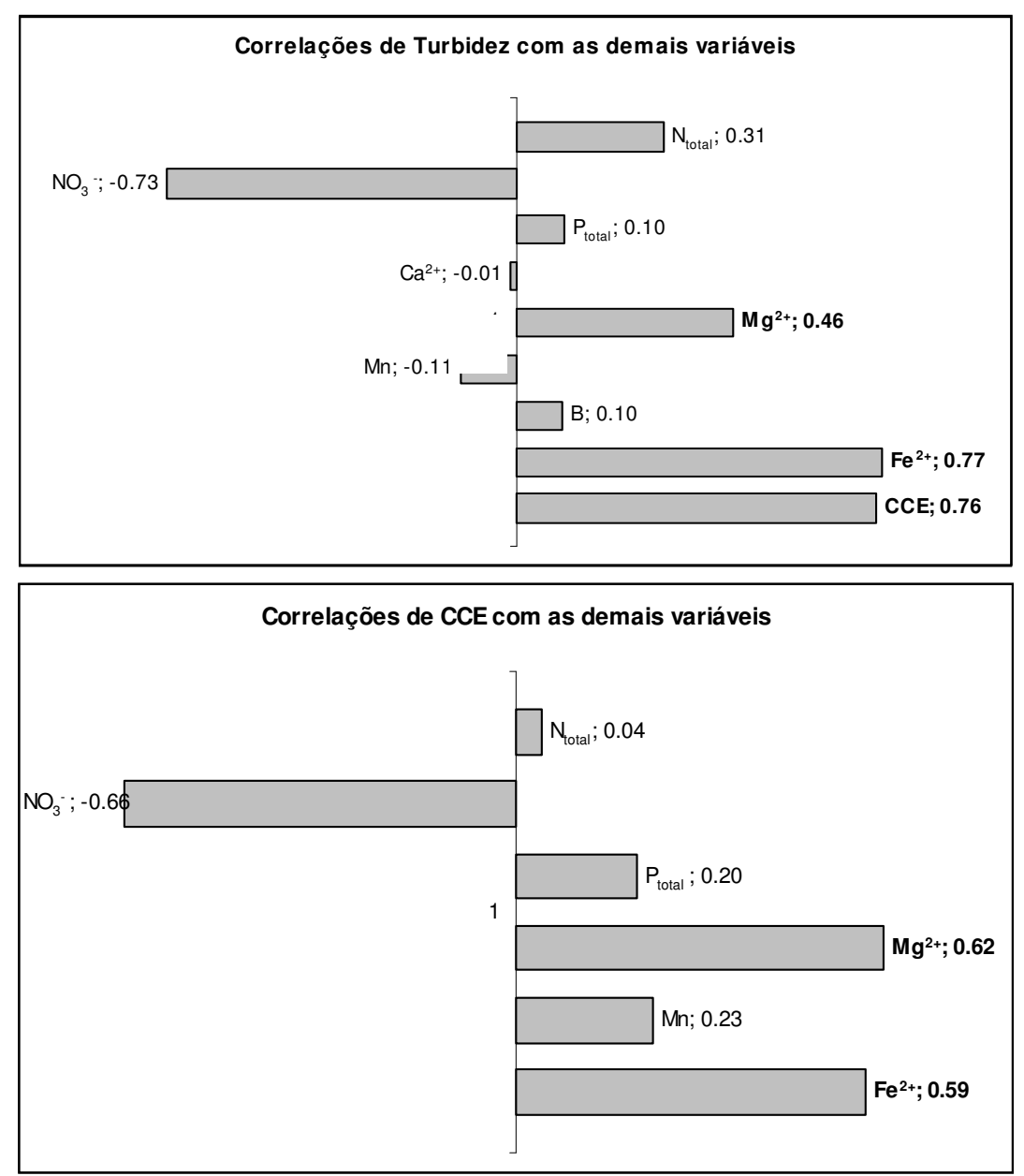

Figura 5. Correlações de turbidez e condutividade elétrica com as demais variáveis

De acordo com a legislação ambiental que "dispõe sobre a classificação dos corpos d'água e diretrizes ambientais para o seu enquadramento, bem como estabelece as condições e padrões de lançamento de efluentes" (CONAMA 375, 2005) foram utilizados os parâmetros vigentes da resolução para verificar o uso preponderante do curso d'água (Tabela 1).

Os resultados máximos das concentrações verificados para as variáveis físico-químicas mostram que somente os sólidos suspensos apresentam concentrações acima do estabelecido pela resolução, sendo de $680 \mathrm{mg} \mathrm{L}^{-1}$. Contudo, a frequiência de concentrações desta magnitude apresentou-se muito abaixo dos valores gerais para o período de estudo.

Segundo o uso preponderante à que se destina atualmente a água da microbacia, pode-se classificar como Classe 3 que pode ser destinada para o abastecimento doméstico, após tratamento convencional, à presença de peixes em geral e outros elementos da fauna e da flora e à dessedentação de animais.

Como a microbacia de estudo destina-se ao reflorestamento de Eucalyptus as variáveis físico-químicas foram analisadas quanto ao possível impacto das práticas silviculturais sobre os recursos hídricos da área.

Os resultados mostraram que somente os sólidos suspensos apresentaram valores acima dos limites extremos de estabilidade, $177 \mathrm{mg} \mathrm{L}^{-1}$, comparado aos resultados verificados para outras microbacias estudadas há vários anos (Lima et al., 2008). Para as demais variáveis analisadas pode-se observar que os valores encontram-se entre os limites de estabilidade (Tabela 2). Logo, tanto para os parâmetros da Resolução CONAMA e para os limites extremos de estabilidade os sólidos em suspensão apresentaram-se superiores.

Para duas microbacias com Eucalyptus também localizadas no Vale do Paraíba foram encontrados na média valores bem inferiores, variando de 12 a $8.5 \mathrm{mg} \mathrm{L}^{-1}$ de sedimento (Ranzini \& Lima, 2002). 
Tabela 1. Média, desvio padrão, valores máximo e mínimo dos parâmetros físico-químicos da água do riacho da microbacia

\begin{tabular}{|c|c|c|c|c|}
\hline Parâmetros & Média & Máximo & Mínimo & $\begin{array}{c}\text { Valores máximos } \\
\text { Resolução CONAMA no } 357\end{array}$ \\
\hline $\mathrm{N}_{\text {total }}\left(\mathrm{mg} \mathrm{L}^{-1}\right)$ & $0,08 \pm 0,05$ & 0,21 & 0,03 & NC* \\
\hline $\mathrm{NO}_{3}^{-}\left(\mathrm{mg} \mathrm{L}^{-1}\right)$ & $1,4 \pm 1,2$ & 3,60 & 0,05 & 10 \\
\hline $\mathrm{NO}_{2}^{-}\left(\mathrm{mg} \mathrm{L}^{-1}\right)$ & $<0,01 \pm 0,0$ & $<0,01$ & $<0,01$ & 1,0 \\
\hline $\mathrm{P}_{\text {total }}\left(\mathrm{mg} \mathrm{L}^{-1}\right)$ & $0,02 \pm 0,03$ & 0,10 & $<0,01$ & 0,15 \\
\hline $\mathrm{Ca}^{2+}\left(\mathrm{mg} \mathrm{L}^{-1}\right)$ & $0,46 \pm 0,41$ & 2,03 & 0,03 & $\mathrm{NC}^{*}$ \\
\hline $\mathrm{Mg}^{2+}\left(\mathrm{mg} \mathrm{L}^{-1}\right)$ & $0,62 \pm 0,31$ & 1,66 & 0,36 & $\mathrm{NC}^{*}$ \\
\hline $\operatorname{Mn}\left(\mathrm{mg} \mathrm{L}^{-1}\right)$ & $0,09 \pm 0,07$ & 0,27 & 0,02 & 0,5 \\
\hline $\mathrm{B}\left(\mathrm{mg} \mathrm{L}^{-1}\right)$ & $0,50 \pm 0,27$ & 1,00 & 0,01 & 0,75 \\
\hline $\mathrm{Fe}^{2+}\left(\mathrm{mg} \mathrm{L}^{-1}\right)$ & $0,06 \pm 0,05$ & 0,15 & 0,003 & 5,0 \\
\hline Turbidez (NTU) & $4,7 \pm 5,2$ & 19,5 & 0,54 & 100 \\
\hline $\operatorname{CCE}\left(\mu \mathrm{S} \mathrm{cm}^{-1}\right)$ & $32,8 \pm 7,2$ & 51,6 & 25,8 & NC* \\
\hline $\mathrm{pH}$ & $7,3 \pm 0,3$ & 8,0 & 6,8 & $6-9$ \\
\hline Sólidos suspensos $\left(\mathrm{mg} \mathrm{L}^{-1}\right)$ & $177 \pm 210$ & 680 & 20,0 & 500 \\
\hline Óleo/graxa $\left(\mathrm{mg} \mathrm{L}^{-1}\right)$ & $<3,0 \pm 0,0$ & $<3,0$ & $<3,0$ & $\mathrm{NC}^{*}$ \\
\hline Óleo mineral (mg L $\left.{ }^{-1}\right)$ & $<3,0 \pm 0,0$ & $<3,0$ & $<3,0$ & $\mathrm{NC}^{*}$ \\
\hline
\end{tabular}

* NC: não consta

Uma provável explicação para a quantidade de sólidos suspensos na microbacia pode advir da erosão que é responsável por $80 \%$ da alteração da qualidade da água, agravado pelas atividades florestais, sendo $90 \%$ dos sedimentos produzidos pela abertura e utilização de estradas (Anderson, 1976). Porém, que o período de estudo sobre as variáveis físico-químicas apresentadas não são suficientes para aferir globalmente a qualidade das atividades de manejo da floresta de Eucalyptus. O estudo apresentado caracterizou-se inicialmente como um estudo de acompanhamento das características gerais da microbacia. Estudos complementares, principalmente durante e após as práticas de manejo florestal devem ser realizadas ao longo de vários anos para se entender melhor os processos hidrológicos da microbacia.

Tabela 2. Limites extremos de estabilidade, segundo a cobertura florestal de microbacias experimentais em comparação à microbacia estudada

\begin{tabular}{|c|c|c|c|c|}
\hline \multirow{2}{*}{ Parâmetros } & \multicolumn{2}{|c|}{ Floresta } & \multirow{2}{*}{ Média Geral } & \multirow{2}{*}{$\begin{array}{l}\text { Microbacia } \\
\text { estudada }\end{array}$} \\
\hline & Nativa & Eucalipto & & \\
\hline Nitrato & $0,00<>2,59$ & $0,22<>2,30$ & $0,12<>2,23$ & 1,4 \\
\hline Fósforo & $0,01<>0,08$ & $0,00<>0,24$ & $0,00<>0,30$ & 0,02 \\
\hline Potássio & $0,28<>2,59$ & $0,29<>1,56$ & $0,24<>2,20$ & ND* \\
\hline Cálcio & $0,55<>2,66$ & $0,88<>2,63$ & $0,68<>3,04$ & 0,46 \\
\hline Magnésio & $0,32<>1,58$ & $0,24<>1,04$ & $0,29<>1,36$ & 0,62 \\
\hline $\mathrm{pH}$ & $6,62<>7,31$ & $5,05<>7,15$ & $5,95<>7,17$ & 7,3 \\
\hline Condutividade & $0,04<>0,08$ & $0,02<>0,08$ & $0,03<>0,08$ & 0,03 \\
\hline Sólidos suspensos & $0,00<>48,30$ & $1,62<>65,48$ & $0,78<>82,68$ & 177 \\
\hline Turbidez & $0,00<>20,37$ & $0,00<>37,05$ & $0,10<>28,47$ & 4,6 \\
\hline Cor & ND* & $0,19<>87,61$ & $0,10<>85,87$ & ND* \\
\hline
\end{tabular}

Fonte: Modificado de Lima et al. (2008); * ND: não disponível 


\section{Considerações Finais}

Somente sólidos suspensos apresentou valores superiores aos limites extremos de estabilidade encontrados para outras microbacias e também aos padrões da Resolução CONAMA 357.

Uma provável hipótese pode ser atribuída à declividade da microbacia, que apresenta relevo forte ondulado a montanhoso. Propostas como redução da malha viária, colheita em mosaicos, maior área de preservação permanente ajudam a minimizar os impactos sobre os recursos hídricos.

\section{Referências}

American Public Health Association. Standart methods for the examination of water and wastewater. $14^{\text {th }}$ ed. Washington, 1979, $1193 \mathrm{p}$.

Anderson, H.W. Forest and water; effects of management on floods, sedimentation, and water supply. USDA. Forest Service. PSW General Technical Report, 18: 1-115, 1976.

Câmara, C. D. Critérios e indicadores para o monitoramento hidrológico de florestas plantadas. 2004. 191p. Tese (Doutorado em Hidráulica e Saneamento) - Escola de Engenharia de São Carlos, USP, São Carlos. 2004.

EMBRAPA. Sistema Brasileiro de Classificação de Solos: Rio de Janeiro: EMBRAPA - SPI - 1999. 412 P.

Feitosa, F.A.C.; Manoel Filho, J. Hidrologia: conceitos e aplicações. 2 ed. Fortaleza: CPRM-REFO, LABHIDUFPE, 2000.

Florenzano, T. G.; Czordas, S. M. Mapa geomorfológico da região do Vale do Paraíba e litoral norte do estado de São Paulo. São José dos Campos: INPE, 1993, 15p. (INPE-5531-PRP/179).

Lima, W.P. Impacto ambiental do eucalipto. São Paulo: EDUSP, 1996. 301p.

Lima, W.P.L.; Fontana, C.R.; Câmara, C.D.; Voigtlaender, M.; Lopes. M.A.F. PROMAB: Histórico, Fundamentos e Conquistas. Documentos Técnicos IPEF: Piracicaba, v.1, n.1, março de 2008.

Mendonça, F. Diagnóstico e análise ambiental de microbacia hidrográfica: Proposição metodológica na perspectiva do zoneamento, planejamento e gestão ambiental. Revista Raega, Curitiba, 3 (3): 67-89, 1999.

Ranzini, M.; Lima, W.P. Comportamento hidrológico, balanço de nutrientes e perdas de solo em duas microbacias reflorestadas com Eucalyptus, no Vale do Paraíba, SP. Scientia Forestalis, Piracicaba, 61: 144159, 2002.

Sentelhas, P.C.; Pereira, A.R.; Marin, F.R.; Angelocci, L.R.; Alfonsi, R.R.; Caramori, P.H.; Swart, S. Balanços hídricos de 500 localidades brasileiras (1999). Núcleo de monitoramento agroclimático, Departamento de Física e Meteorologia da ESALQ/USP: Disponível em: <http://lce.esalq.usp.br>. Acesso em: 03 nov. 2008.

Strahler, A.N. Quantitative analysis of watershed geomorphology. Trans. Am. Geophys. Un., 38:913-920, 1957.

Von Sperling, E. Qualidade da água em atividades de mineração. In.: DIAS, L. E.; MELO, J.W.V. (Org.). Recuperação de áreas degradadas. Viçosa: Sociedade Brasileira de Áreas Degradadas, 1998. p. 95-105. 